\title{
Cardiovascular outcomes of continuous positive airway pressure therapy for obstructive sleep apnea
}

\author{
Yüksel Peker ${ }^{1,2,3,4}$, Baran Balcan ${ }^{5}$ \\ ${ }^{1}$ Department of Pulmonary Medicine, School of Medicine, Koc University, Istanbul, Turkey; ${ }^{2}$ Department of Clinical Sciences, Respiratory Medicine \\ and Allergology, Faculty of Medicine, Lund University, Lund, Sweden; ${ }^{3}$ Sahlgrenska Academy, University of Gothenburg, Gothenburg, Sweden; \\ ${ }^{4}$ Division of Pulmonary, Allergy, and Critical Care Medicine, University of Pittsburgh School of Medicine, Pittsburgh, PA, USA; ${ }^{5}$ Department of \\ Pulmonary Medicine, School of Medicine, Marmara University, Istanbul, Turkey \\ Contributions: (I) Conception and design: All authors; (II) Administrative support: All authors; (III) Provision of study materials or patients: All \\ authors; (IV) Collection and assembly of data: All authors; (V) Data analysis and interpretation: All authors; (VI) Manuscript writing: All authors; (VII) \\ Final approval of manuscript: All authors. \\ Correspondence to: Yüksel Peker, MD, PhD. Professor, Department of Pulmonary Medicine, Koc University Hospital, School of Medicine, Koc \\ University, Topkapi mah Davutpasa cad No 4, TR 34010 Zeytinburnu, Istanbul, Turkey. Email: yupeker@ku.edu.tr or yukselpeker26@gmail.com.
}

\begin{abstract}
Obstructive sleep apnea is a common disorder with increased risk for cardiovascular morbidity and mortality. The first choice of treatment of obstructive sleep apnea is continuous positive airway pressure, which reduces excessive daytime sleepiness and improves quality of life in sleep clinic cohorts. Nevertheless, the majority of patients with cardiovascular disease and concomitant obstructive sleep apnea do not report daytime sleepiness, and adherence to treatment is insufficient particularly in this group. The current article aims to give an updated overview of the impact of continuous positive airway pressure therapy on cardiovascular outcomes mainly based on the observational studies and the recent randomized controlled trials.
\end{abstract}

Keywords: Obstructive sleep apnea (OSA); cardiovascular outcomes; continuous positive airway pressure (CPAP); randomized controlled trial (RCT)

Submitted Mar 20, 2018. Accepted for publication Sep 10, 2018.

doi: $10.21037 /$ jtd.2018.11.48

View this article at: http://dx.doi.org/10.21037/jtd.2018.11.48

\section{Introduction}

Obstructive sleep apnea (OSA) is a highly common condition (23.4\% of women, $49.7 \%$ of men) based on the recent largest population study (HypnoLaus cohort) (1), adapting an apnea-hypopnea-index (AHI) of at least 15/h, according to the American Academy of Sleep Medicine 2012 scoring criteria (2). When excessive daytime sleepiness (EDS), defined as an Epworth sleepiness scale (ESS) score $>10$ was included, the prevalence of AHI $\geq 5 / h$ with EDS was $5.9 \%$ in women, and $12.5 \%$ in men (1). The prevalence is even higher in clinical cohorts with cardiovascular disease (CVD) (3). The first choice of treatment of OSA is continuous positive airway pressure (CPAP), which reduces EDS and improves quality of life (4). However, the majority of patients with CVD and concomitant OSA do not report EDS, and adherence to CPAP is challenging particularly in this group. Other treatment modalities for OSA include active weight loss for individuals with obesity, oral appliance therapy (OAT), surgical approaches (i.e., uvulopalatopharyngoplasty or maxillofacial surgery), nervus hypoglossus stimulation (5). Weight loss in obese OSA patients has shown to result in a reduction of AHI and improved sleep efficiency (6). Moreover, avoidance of the supine sleeping position may reduce $\mathrm{AHI}$ in patients with mild, position-dependent OSA (7). To date, there is no efficient pharmacological therapy for OSA. Positive effects of weight reduction on cardiovascular outcomes was recently reviewed by Hudgel (8), a systematic review of effect of surgical treatment on cardiovascular outcomes 
was published by Halle et al. (9), and an intensive systematic review and meta-analysis of the cardiovascular effects of OAT was recently published by de Vries et al. (10). The current review focuses on the literature regarding the observational studies and randomized controlled trials (RCT) addressing the impact of CPAP treatment on cardiovascular outcomes.

The mechanisms involved in the cardiovascular consequences of OSA have been widely reviewed (3). Sleep fragmentation and intermittent hypoxia may trigger sympathetic overstimulation, oxidative stress, vascular inflammation, endothelial dysfunction, arterial stiffness, hypercoagulation, which all may cause atherosclerosis and development of CVD. Thus, efficient treatment of the underlying OSA would eliminate the increased risk burden. Despite the demonstrated beneficial effect of the CPAP treatment of OSA on cardiovascular outcomes in the great majority of the prospective observational studies, the results from the RCTs have been conflicting.

\section{Impact of CPAP therapy on cardiovascular mechanisms}

Individual studies cited in this overview addressing the effect of CPAP treatment on cardiovascular mechanisms are summarized in Table 1. Other studies not shown in the Table 1 are included in the meta-analyses referred under the corresponding sections below.

\section{Sympathetic overstimulation and autonomic dysfunction}

\section{Observational studies}

Early observational studies with CPAP therapy have suggested that efficient treatment may reduce the increased sympathetic activity in OSA patients $(11,12)$, not only during sleep but also during daytime, especially in hypertensive OSA (13). In another observational study, Narkiewicz et al. (14) measured blood pressure (BP), heart rate and muscle sympathetic nerve activity (MSNA) in 11 normotensive, otherwise healthy patients with OSA who were treated with CPAP. The measurements were obtained at baseline, and repeated after 1 month, 6 months, and 12 months of CPAP treatment, and the values were compared with those recorded in nine otherwise healthy untreated OSA patients. While BP and heart rate did not change over time in both treated and untreated patients, there was a significant decrease in MSNA in the CPAP group, and this decrease was evident after both 6 and 12 months of CPAP therapy. The authors concluded that CPAP treatment decreased the MSNA in patients with OSA, and this reduction was evident first after an extended duration of therapy (14). In another prospective observational study, Pinto et al. (15) addressed the impact of one month of CPAP treatment on plasma nitrate and urinary norepinephrine levels in 36 patients with mild-to-moderate OSA and 31 patients with severe OSA, and found significant improvements in the severe OSA group but not in the individuals with mild-to-moderate OSA. There is also data suggesting that effective CPAP treatment may reverse the impaired autonomic dysfunction in OSA patients. Moreover, CPAP withdrawal even for one week was associated with a marked increase in sympathetic activity (47). More recently, Henderson et al. (16) studied the impact of CPAP treatment on MSNA and its relationship with brainstem activity measured by magnetic resonance imaging in 15 control and 15 OSA subjects before and after 6 and 12 months of CPAP treatment in the OSA group (16). The researchers found that MSNA was greatly elevated in patients with OSA, and there was significant reduction after CPAP treatment. Moreover, this MSNA reduction was associated with restoration of MSNA-related brainstem activity and structural changes in the medullary raphe, rostral ventrolateral medulla, dorsolateral pons, and ventral midbrain after 6 and 12 months of CPAP treatment (16).

\section{RCTs}

Among the eight RCTs included in a well-summarized review by Jullian-Desayes et al. (48), CPAP treatment had a beneficial effect of CPAP on sympathetic activity in five studies. In a parallel-designed RCT among 38 patients with OSA, Ziegler et al. demonstrated that 10 days of CPAP treatment was associated with a significant decrease in daytime catecholamine levels while no significant change was observed in the sham-CPAP group (17). The researchers noted that daytime sympathetic nervous activation was greater in patients with more severe OSA, and that CPAP treatment diminished the daytime sympathetic activity while the potential nighttime effect of CPAP treatment was masked by a small placebo effect (17). In another parallel-designed RCT among 50 patients with OSA, Mills et al. (18) randomized 17 patients to CPAP, 16 to sham-CPAP, and 17 to nocturnal oxygen therapy for 2 weeks, respectively. CPAP treatment resulted in significant reductions in plasma norepinephrine levels both by increases in norepinephrine clearance and decreases in diurnal and nocturnal excretion compared with the changes in the other groups (18). In a larger cohort of 102 men with 


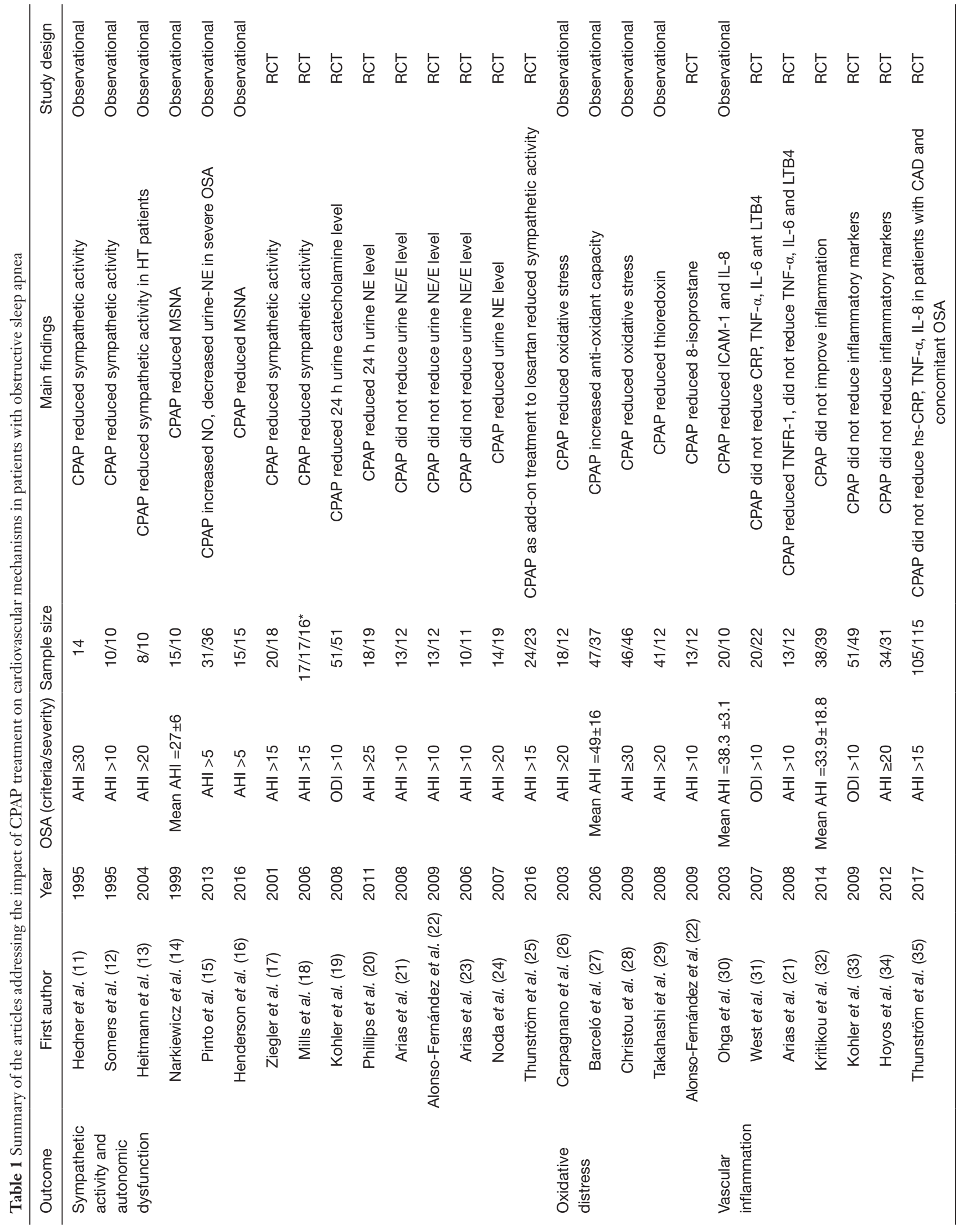




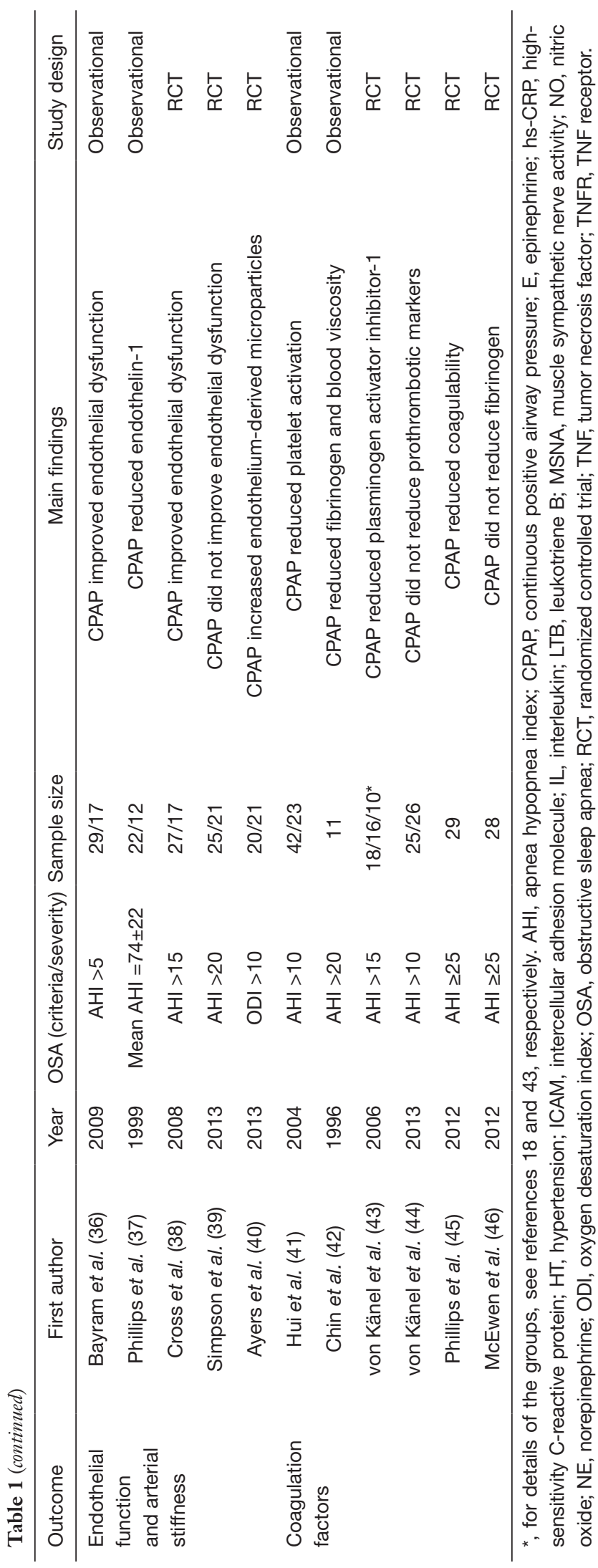

OSA, Kohler et al. (19) randomized 51 patients to CPAP and 51 to sham-CPAP for 4 weeks, and demonstrated significant reductions in 24-h urinary catecholamine excretion as well as improvements in baroreflex sensitivity. In a later study by Phillips et al. (20), 28 patients with OSA completed an RCT in a cross-over design, treated by CPAP and sham-CPAP for 2 months, respectively, with a 1 month of wash-out period between the treatment arms. The primary outcome was post-prandial lipidemia, and among secondary outcome studied, 24-h and awake urinary norepinephrine levels were decreased significantly while no changes were observed regarding urinary epinephrine and asleep norepinephrine levels (20). In contrary, Arias et al. (21) showed no significant difference regarding the urinary epinephrine and norepinephrine levels in 25 OSA patients randomized to CPAP $v$ s. sham-CPAP in a crossover designed study for 12 weeks, respectively. Likewise, in an exactly similar designed crossover RCT, no significant changes in urinary catecholamine levels were observed in 25 OSA patients randomized to CPAP vs. sham-CPAP for 12 weeks, respectively (22). Moreover, in another cross-over designed RCT by Arias et al. (23), addressing the impact of CPAP primarily on pulmonary hypertension, no significant changes were observed regarding the urinary catecholamine levels in 21 OSA patients randomized to CPAP vs. sham-CPAP for 12 weeks, respectively. These neutral trials (21-23) were criticized for the cross-over design for not including a wash-out period, and thus for a potential carry-over effect as a major limitation (48). Among other RCTs not included in that review (48), the study by Noda et al. (24) addressing the impact of CPAP on daytime baroreflex sensitivity and nitric oxide production in patients with moderate to severe OSA is also noteworthy. The researchers randomized 14 patients to CPAP for 12 weeks, and 19 patients to no-CPAP showing a significant reduction in the 24-h urinary excretion of norepinephrine as well as significant increase in the daytime baroreflex sensitivity in the CPAP group while there were no significant changes in the control group. More recently, Thunström et al. (25) addressed the cardiovascular mechanisms involved in response to an angiotensin II receptor antagonist, losartan, and CPAP as add-on treatment for hypertension and OSA. Newly diagnosed hypertensive patients with or without OSA were treated with losartan $50 \mathrm{mg}$ daily during a 6-week, parallel-design study, and in the second 6-week, the OSA patients continued to receive losartan and were randomly assigned to either CPAP or to no-CPAP. Losartan significantly increased renin levels and reduced 
aldosterone levels in the group without OSA while there was no significant decrease in aldosterone levels among OSA patients. Add-on CPAP treatment tended to lower aldosterone levels, but reductions were more pronounced and significant in measures of sympathetic activity (25).

\section{Evidence level}

As summarized above and in Table 1, the majority of the studies in literature supports that CPAP treatment reduces the sympathetic over-activity in adults with OSA.

\section{Oxidative stress}

\section{Observational studies}

Carpagnano et al. (26) demonstrated higher concentrations of 8-isoprostane in the morning exhaled condensate and plasma of OSA patients compared to concentrations in the healthy obese subjects, and these elevations were observed in the morning but not in the evening, suggesting an association with the nocturnal apneic events. The researchers reported a significant reduction after CPAP therapy (26). An increase in antioxidant capacity has also been suggested in OSA patients after 12 months of CPAP treatment among the ones who were adherent to CPAP (27). In another observational study, Christou et al. (28) evaluated oxidative stress markers in blood samples with a commercially available assay in 46 patients with severe OSA, showing increased levels compared with those in 46 controls with no-OSA or mild-to-moderate OSA. The levels of the oxidative stress markers were decreased in the morning following the CPAP titration night, and this reduction was further preserved after 2 months of CPAP treatment (28). Thioredoxin, which is a novel oxidative stress marker, was reduced after 1 month of CPAP treatment in 27 patients with severe OSA (29).

\section{RCTs}

Alonso-Fernández et al. (22) included 31 patients with OSA in a cross-over design and showed a significant reduction in 8-isoprostane levels and increase in nitrates after 12 weeks of CPAP treatment compared to sham CPAP. However, major concerns with this study were exclusion of the patients with CPAP use $<3.5 \mathrm{~h} / \mathrm{night}$, and lack of a wash-out period between the treatment arms.

\section{Evidence level}

There is yet not sufficient number of RCTs to suggest a beneficial effect of CPAP treatment regarding oxidative stress in adults with OSA.

\section{Vascular inflammation}

\section{Observational studies}

Many studies have assessed a wide group of circulating inflammatory mediators, but mainly C-reactive protein (CRP) and interleukin (IL)-6. Guo et al. (49) performed a meta-analysis focused on the effect of CPAP treatment on CRP involving 1,199 OSA patients from 14 observational studies. The meta-analysis indicated that the overall standardized mean difference (SMD) for the CRP levels was 0.64 units [95\% confidence interval (CI), 0.40-0.88] before and after CPAP therapy. Subgroup analysis showed that the decrease in CRP levels was significant first after 3 months of CPAP treatment with a further decline after 6 months (49). Another meta-analysis by Baessler et al. (50) included a total of 14 studies with 771 patients pooled for CRP; nine studies with 209 patients pooled for tumor necrosis factor (TNF)- $\alpha$, and eight studies with 165 patients pooled for IL-6, and demonstrated significant improvement in the levels of CRP and TNF- $\alpha$, and a trend towards improvement in the levels of IL-6 after CPAP treatment (50). Likewise, the meta-analysis performed by Xie et al. (51) included 35 studies involving 1,985 OSA patients; 24 studies on CRP, 16 studies on IL-6, three studies on IL-8, and 12 studies on TNF- $\alpha$. The results showed significant improvements in all studied inflammatory biomarkers, and the subgroup analyses demonstrated better benefits with therapy duration of at least 3 months, and for patients using CPAP at least $4 \mathrm{~h}$ /night (51). Among other inflammatory biomarkers, levels of circulating intercellular adhesion molecule (ICAM)-1, which mediates adhesion of leucocytes to the vascular endothelium, was also reduced in OSA patients after CPAP treatment (30).

\section{RCTs}

West et al. (31) randomized 42 men with diabetes mellitus and newly diagnosed OSA to either CPAP or sham-CPAP for 3 months in parallel design in order to primarily address the impact of CPAP treatment on glycaemic control and insulin resistance and found no significant effect. CRP and adiponectin values did not either change significantly. However, the overall compliance was relatively low in both arms (31). In the study of Arias et al. (21), 25 male OSA patients were randomized to CPAP $v s$. sham-CPAP in a cross-over design for 12 weeks, respectively, TNF receptor (TNFR)-1 levels significantly decreased in compliant CPAP patients. CPAP treatment had no significant effect 
on TNF- $\alpha$, IL-6 and leukotriene B4 levels (21). However, Kritikou et al. (32) did not confirm the changes in TNFR-1 in a cohort of 25 middle-aged men and women randomized to CPAP vs. sham-CPAP in a cross-over design for 2 months, respectively. CPAP failed to have significant impact on the other inflammatory biomarkers, CRP, IL-6, leptin and adiponectin despite a good CPAP adherence level in the whole group (32). Another RCT by Kohler et al. (33) also failed to show any significant effect of 4 weeks of CPAP treatment in 49 men with moderate to severe OSA compared with subtherapeutic CPAP for 4 weeks in 51 men with the same degree of OSA. The measured inflammatory markers were CRP, IL-6, adiponectin and interferon gamma (33). Hoyos et al. (34) randomized 65 non-diabetic men with moderate to severe OSA to CPAP or shamCPAP for 12 weeks, and studied cardiometabolic variables including blood leptin and adiponectin concentrations. The researchers found no between-group differences at 12 weeks compared to the baseline values (34). Moreover, Kohler et al. (52) did not show an increase in inflammatory biomarkers (CRP, IL-6, IL-8, TNF-a) after CPAP withdrawal for 2 weeks. More recently, Thunström et al. (35) demonstrated no significant beneficial effect of CPAP over 12 months on the inflammatory biomarkers in the RICCADSA (Randomized Intervention with CPAP in Coronary Artery Disease and Obstructive Sleep Apnea) cohort, except for IL-6 levels, which reduced to the same extent in both CPAP and no-CPAP groups. No between-group differences were observed regarding the CRP, IL- 8 and TNF-a values, and there was no significant association between CPAP adherence and changes in the inflammatory biomarker levels in this CAD population with nonsleepy OSA (35).

\section{Evidence level}

The results of several meta-analyses of the observational studies suggest significant improvements in the majority of the studied inflammatory biomarkers, and the subgroup analyses demonstrate better benefits with therapy duration of at least 3 months, and for patients using CPAP at least $4 \mathrm{~h} /$ night, in sleep clinic cohorts. However, results of the RCTs are not supportive for these conclusions, probably due to relatively small sample sizes, and inclusion of individuals from different clinical cohorts with already established CVDs.

\section{Endothelial function and arterial stiffness}

\section{Observational studies}

Bayram et al. (36) reported that 6 months of CPAP treatment resulted in improvement in endothelial function in normotensive men compared to untreated OSA patients with similar endothelial dysfunction findings at baseline without changes at follow-up. It was also shown that endothelial function was worsened after CPAP withdrawal to the baseline values, supporting the fact that reversal of this dysfunction is dependent on ongoing CPAP use. Increased level of nitric oxide NO and reduced level of endothelin-1 were also documented in OSA patients following CPAP treatment (37).

\section{RCTs}

Cross et al. (38) measured endothelial function and impact of 6 weeks of CPAP treatment in a randomized, double blind, placebo controlled, cross-over trial among OSA patients with frequent versus less desaturations, and showed a beneficial effect especially in the desaturating OSA patients. In a later study, Simpson et al. (39) randomized 50 men with OSA and without diabetes to either CPAP $(n=25)$ or sham-CPAP $(n=25)$ in a parallel-designed, 12 -week double-blind study and addressed the effect of treatment on circulating progenitor cells (CPCs) isolated from blood, measured by flow cytometry, and endothelial function, assessed by peripheral arterial tonometry. Neither CPCs nor endothelial function improved significantly after CPAP treatment despite the efficient elimination of the obstructive events by CPAP (39). On the other hand, in another RCT, Ayers et al. (40) demonstrated that a 2-week withdrawal of CPAP treatment increased the endotheliumderived microparticles, suggesting that microparticle formation may be causally linked to OSA and may promote endothelial activation (40).

\section{Evidence level}

Despite positive findings shown in the observational studies, the results from the few RCTs conducted within this area are not sufficient to support a beneficial effect of CPAP on endothelial function in adults with OSA.

\section{Coagulation factors}

\section{Observational studies}

Early observational reports were conflicting regarding the effect of CPAP therapy on coagulation factors. CPAP decreased platelet activation (41), and fibrinogen levels (42).

\section{RCTs}

OSA has been associated with an increased risk of 
atherothrombotic events, and a few studies investigated OSA patients' day/night rhythm of several prothrombotic markers in OSA patients and potential changes with CPAP. von Känel et al. (43) showed that CPAP reduced plasminogen activator inhibitor-1 but had no significant impact on hematocrit, whole blood viscosity and other coagulation factors in OSA patients. In another RCT, the same research group showed no significant differences in changes of periodic pattern and in day/night rhythm parameters of prothrombotic markers pre- to post-treatment between the 3 weeks of CPAP and sham-CPAP (44). In the randomized cross-over trial by Phillips et al. (45), 28 patients received CPAP or sham CPAP, each for 2 months with a 1-month washout between treatments. After each treatment period, CPAP reduced the early morning level of von Willebrand factor, and nocturnal levels of factor VIII and factor V. On the other hand, there was no difference in fibrin generation between CPAP and sham-CPAP groups in the RCT by McEwen et al. (46).

\section{Evidence level}

Results from the existing reports are inconclusive and not sufficient to support a beneficial effect of CPAP on coagulation factors patients with OSA.

\section{Impact of CPAP therapy on CVDs and mortality}

Individual studies cited in this overview addressing the effect of CPAP treatment on CVDs and mortality are summarized in Table 2. Other studies not shown in the Table 2 are included in the meta-analyses referred under the corresponding sections below.

\section{Systemic bypertension}

Earlier meta-analyses suggested that CPAP is effective in reducing $\mathrm{BP}$ both in normotensive and hypertensive OSA subjects although the significance of reduction has been higher in the hypertensive patients (97). Moreover, the studies demonstrated significant reductions in nocturnal and daytime BP especially in OSA patients with therapyresistant hypertension (97). It has also been suggested that "non-dipping" hypertensive OSA patients may convert to "dippers" after CPAP treatment, thereby, restoring the physiological nocturnal dipping BP pattern (53). Indeed, a 24-month follow-up study demonstrated a dose dependent $\mathrm{BP}$ response to CPAP treatment supporting that beneficial effect can be achieved in long-term even in the initially incompletely treated hypertensive OSA subjects (54). On the other hand, neutral findings have been reported in an RCT addressing the effect of 8-week of CPAP treatment on BP in mild OSA (55). In another RCT, conducted in hypertensive OSA patients with no sleepiness, CPAP did not reduce $\mathrm{BP}$ (56). These earlier studies have also raised the question whether or not the duration of CPAP treatment plays a major role in this context. In general, greater $\mathrm{BP}$ response to CPAP treatment has been associated with CPAP compliance, severity of OSA, daytime sleepiness, and the co-existence of initial hypertension (97).

The results from the more recent RCTs and metaanalyses suggest that CPAP significantly reduces $\mathrm{BP}$ in OSA patients. Studies using 24-h BP monitoring (97-102) have shown a decline of 2 to $2.5 \mathrm{mmHg}$ in systolic BP, and 1.5 to $2 \mathrm{mmHg}$ in diastolic BP, respectively, compared with controls, as illustrated in a recent review by Javaheri et al. (3). Greater reductions were shown in patients with therapy-resistant hypertension (between 4.7 to $7.2 \mathrm{mmHg}$ for systolic BP, and 2.9 to $4.9 \mathrm{mmHg}$ for diastolic BP, respectively) $(3,57-61,103,104)$.

In one RCT, conducted in a primary care cohort with new-onset hypertension, Durán-Cantolla et al. (62) chose CPAP treatment as a single therapy compared with sham-CPAP, showing a small reduction in 24-h BP (2.1 $\mathrm{mmHg}$ for systolic BP, and $1.3 \mathrm{mmHg}$ for diastolic BP). In another RCT, Pépin et al. (63) compared CPAP with an angiotensin II receptor antagonist, valsartan, in a crossover design. Valsartan was superior to CPAP in lowering BP, and a small but significant reduction was also observed in the CPAP group. After the first part of the study, valsartan and CPAP were combined in a subgroup of patients with uncontrolled BP in the observational, open-label arm of the study, and demonstrated an additional reduction in 24-h BP (63). More recently, Thunström et al. (64) addressed the impact of another angiotensin II receptor antagonist, losartan, among patients with newly diagnosed hypertension with and without OSA. The BP drop was significantly less in those with OSA than without. CPAP treatment in addition to losartan resulted in a significant decrease in BP, especially among those who used the device at least $4 \mathrm{~h} /$ night (64).

\section{Evidence level}

Existing literature, overwhelmed by observational studies, and several well-done RCTs addressing the impact CPAP suggest a beneficial BP lowering effect, especially in nocturnal BP, and especially among OSA patients with 


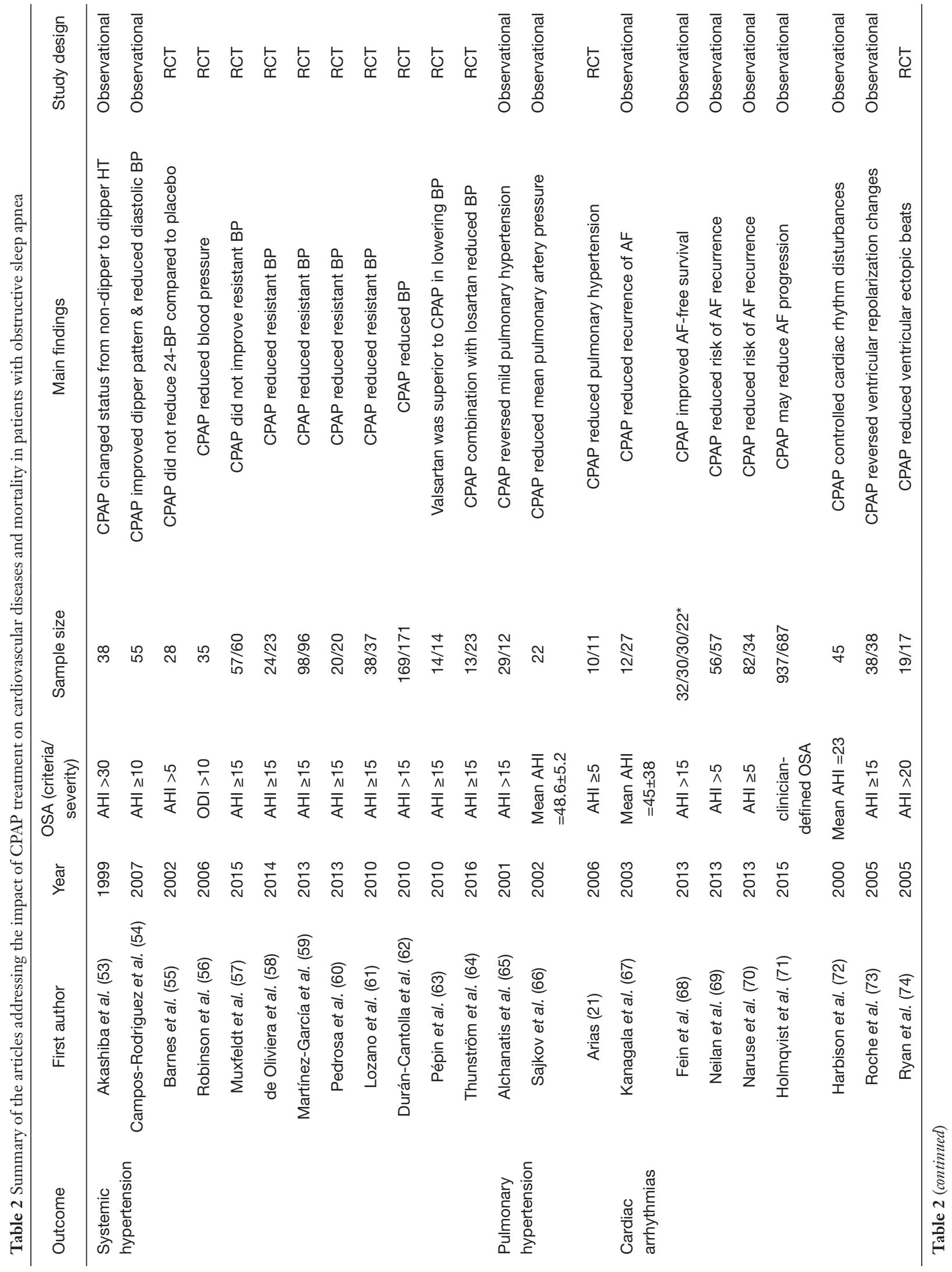




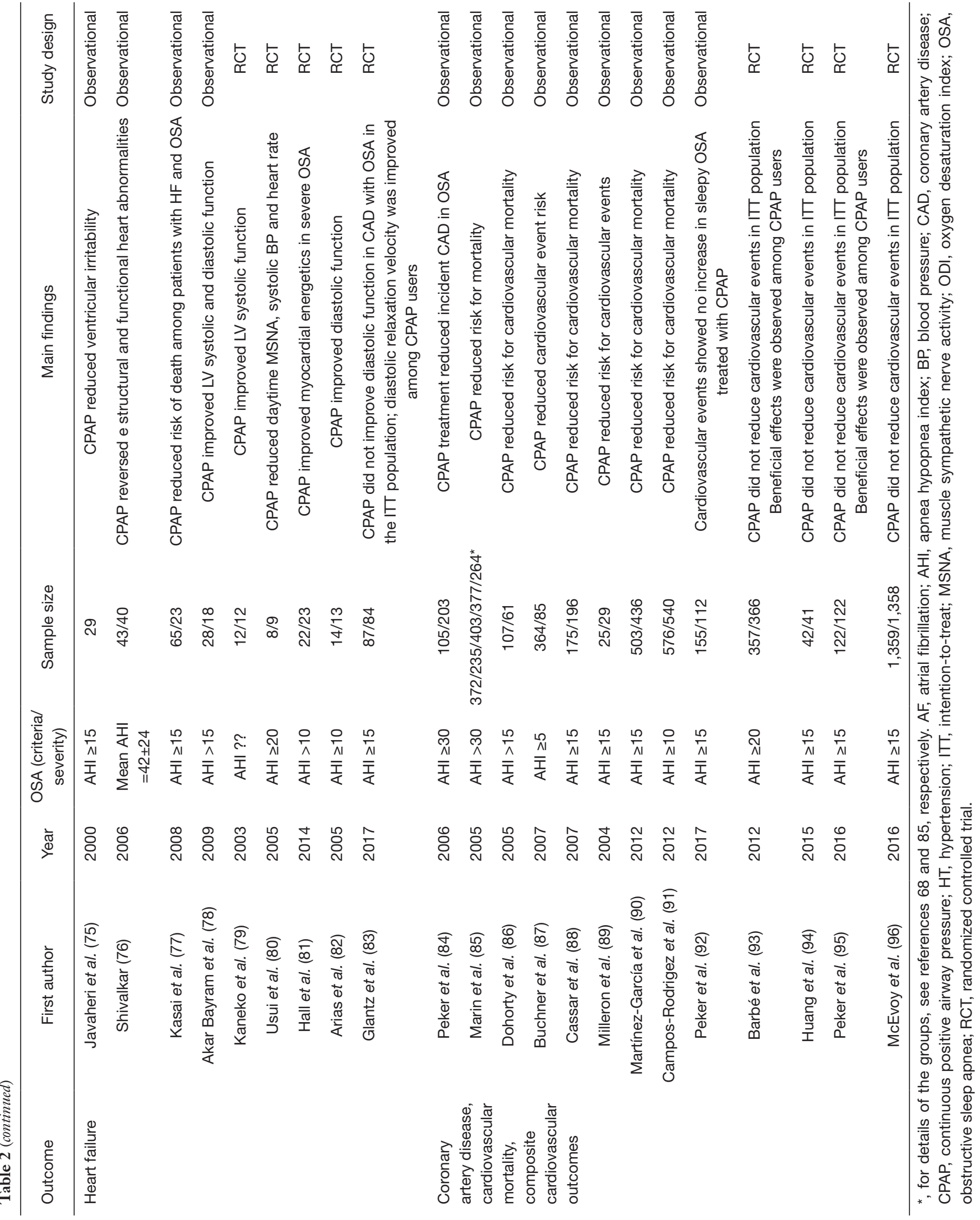


therapy-resistant hypertension. Moreover, CPAP as "addon" treatment to antihypertensive medication seems to be an effective therapy option.

\section{Pulmonary arterial hypertension}

\section{Observational studies}

In an early observational study, Alchanatis et al. (65) demonstrated that 6 months of CPAP treatment improves pulmonary hypertension in patients with OSA. Other observational studies have also shown that treating OSA with CPAP improves pulmonary hypertension (105). Moreover, increased pulmonary vascular reactivity to hypoxia was also reversed by CPAP treatment in pulmonary hypertension patients with concomitant OSA (66).

\section{RCTs}

In a smaller RCT with CPAP vs. sham-CPAP in 23 patients with OSA and concomitant pulmonary hypertension, effective CPAP treatment for a 12 -week period was associated with significant improvements in echocardiographic measurements of pulmonary arterial pressure (from a mean of 30 to $24 \mathrm{mmHg}$ ) (23).

\section{Evidence level}

Existing literature is not sufficient to draw proper conclusions regarding the impact of CPAP on pulmonary hypertension among patients with OSA.

\section{Cardiac arrbythmias}

\section{Observational studies}

Among patients with atrial fibrillation (AF) converted to sinus rhythm with electrical cardioversion, the rate of recurrence of the $\mathrm{AF}$ within 1 year was significantly higher in inadequately treated OSA patients compared to the efficiently treated subjects (67). Similarly, Fein et al. (68) showed that CPAP therapy resulted in higher AF-free survival rate $(71.9 \%$ vs. $36.7 \% ; \mathrm{P}=0.01)$ and $\mathrm{AF}$-free survival off antiarrhythmic drugs or repeat ablation following pulmonary vein isolation (PVI) $(65.6 \%$ vs. $33.3 \%$; $\mathrm{P}=0.02)$. $\mathrm{AF}$ recurrence rate of CPAP-treated patients was similar to a group of patients without OSA [hazard ratio (HR) 0.7, $\mathrm{P}=0.46]$ (68). Neilan et al. (69) investigated a consecutive group of 720 patients undergoing a cardiac magnetic resonance study before PVI, and demonstrated that OSA patients had an increased BP, pulmonary artery pressure, right ventricular volume, left atrial size, and left ventricular mass, and that CPAP therapy was associated with a better cardiac structure in these parameters as well as with a lower risk of AF recurrence after PVI (69). Likewise, Naruse et al. (70) showed that OSA patients treated with CPAP had a lower recurrence of AF after ablation compared with that in untreated OSA. In a registry-based study, including 10,132 patients in the Outcomes Registry for Better Informed Treatment of Atrial Fibrillation (ORBIT$\mathrm{AF}$ ) and followed for up to 2 years, Holmqvist et al. (71) showed that patients with OSA on CPAP treatment were less likely to progress to more permanent forms of $\mathrm{AF}$ compared with patients without CPAP (HR 0.66; 95\% CI, 0.46-0.94). A meta-analysis, including eight studies with OSA patients (698 CPAP users and 549 non-CPAP users), demonstrated in a random effects model that patients treated with CPAP had a $42 \%$ decreased risk of AF (pooled risk ratio, 0.58 ; 95\% CI, 0.47-0.70) (106). A recent expert consensus document on AF identified OSA as a risk factor for AF recurrence after surgical and catheter ablation, and recommended treatment of the OSA (107). The incidence and the severity of ventricular arrhythmias were also reduced by CPAP treatment (72). Furthermore, ventricular repolarization changes, which may contribute to higher ventricular irritability, were reversed by CPAP treatment (73).

\section{RCTs}

In patients with OSA and systolic dysfunction, an RCT suggested a $58 \%$ reduction in the frequency of ventricular premature complexes during sleep after 1 month of CPAP therapy (74).

\section{Evidence level}

Existing literature is mainly based on observational studies suggesting that CPAP may help maintaining sinus rhythm after electrical cardioversion and ablation in patients with AF. Nevertheless, there is a lack of RCTs to draw proper conclusions in this context.

\section{Heart failure}

\section{Observational studies}

Javaheri (75) showed that the first-night CPAP treatment was effective in eliminating sleep apnea in $55 \%$ of 29 male cardiac failure patients with sleep apnea. Longterm effects of CPAP have also been studied. Altered cardiac functions and structural changes in heart failure patients with concomitant OSA were improved after 6 months of 
CPAP treatment (76). Kasai et al. (77) showed that the risk for death and hospitalization was significantly higher among untreated and less CPAP-complaint OSA patients compared to that among efficiently treated OSA subjects. Akar Bayram et al. (78) indicated a significant improvement in left ventricular systolic and diastolic dysfunction after 6 months of CPAP treatment in 28 newly diagnosed moderate to severe OSA patients who were free of structural heart disease, pulmonary disease, diabetes mellitus, dyslipidemia, alcoholism, neuromuscular disease, renal failure or malignancy at baseline.

\section{RCTs}

Kaneko et al. (79) studied 24 heart failure patients [left ventricular ejection fraction (LVEF) $<45 \%$ ] and concomitant OSA who were receiving optimal medical treatment. Echocardiographic measurements were assessed on the following morning after polysomnography and after 1 month of CPAP treatment $(n=12)$ or no-CPAP $(n=12)$, and average $\mathrm{LVEF}$ was increased from $25.0 \% \pm 2.8 \%$ to $33.8 \% \pm 2.4 \%(\mathrm{P}<0.001)$ in the CPAP group (79). In a smaller RCT, Usui et al. (80) studied MSNA, BP and heart rate of medically treated heart failure patients (ejection fraction $<45 \%$ ) and concomitant OSA (AHI $\geq 20$ ) in the morning after overnight polysomnography, and repeated the studies 1 month later in patients who were randomized to CPAP ( $n=8)$ or no-CPAP (n=9). Significant benefits were shown in the CPAP group regarding the reductions in daytime MSNA, systolic BP and heart rate. Hall et al. (81) evaluated 45 cardiac failure patients with OSA using $11 \mathrm{C}$-acetate and 11C-hydroxyephedrine positron emission tomography before and 6 to 8 weeks of CPAP $(n=22)$ or no CPAP $(n=23)$, and CPAP improved myocardial energetics in the severe OSA cases (81). Regarding heart failure with preserved ejection fraction and concomitant OSA, Arias et al. (82) randomized 27 consecutive OSA patients to CPAP or sham-CPAP in a double-blind, crossover design for 12 weeks, and demonstrated significant improvement in diastolic function in the CPAP group. A more recent RCT by Glantz et al. (83) showed no significant changes after 1 year in diastolic function parameters in the RICCADSA cohort randomized to CPAP compared with the no-CPAP group in the intention-to-treat (ITT) analysis. However, post-hoc on-treatment analysis revealed a significant association between CPAP usage for $\geq 4 \mathrm{~h} /$ night and an increase in diastolic relaxation velocity (odds ratio 2.3, 95\% CI, 1.0-4.9; $\mathrm{P}=0.039$ ) after adjustment for age, sex, BMI, and left atrium diameter at baseline (83).

\section{Evidence level}

Some beneficial effects of CPAP have been shown in patients with heart failure and co-existing OSA but more RCTs with larger samples are needed, especially among patients with preserved ejection fraction and OSA.

\section{Coronary artery disease, cardiovascular mortality, composite cardiovascular outcomes}

\section{Observational studies}

In a prospective observational study of the incident CAD in a sleep-clinic cohort, efficient treatment of OSA had a protective effect (84). In an observational 10-year follow-up study of males from a sleep clinic cohort, Marin et al. (85) suggested untreated severe OSA (AHI $>30 / \mathrm{h}$ ) as an independent predictor for cardiovascular mortality while the patients treated with CPAP showed a significantly lower non-fatal and fatal cardiovascular event incidence rates similar to those in the general population. In another observational study, Doherty et al. (86) demonstrated a protective effect of the treatment in a cohort of 168 OSA patients over 7.5 years. In a larger OSA population, Buchner et al. (87) suggested that efficient CPAP treatment was associated with a $64 \%$ reduction in cardiovascular events independent of age, gender, cardiovascular risk factors and baseline comorbidities at 6-year follow-up. In another observational cohort study, Cassar et al. (88) found significantly lower incidence of cardiovascular death in OSA patients treated with CPAP following percutaneous coronary intervention (PCI) compared with the untreated OSA patients. In another observational study, Milleron et al. (89) demonstrated a significant reduction in the composite cardiovascular end-point (incidence of new coronary events, acute coronary syndrome, hospitalization for cardiac failure and coronary revascularization requirement as well as cardiovascular mortality) in CAD patients with treated OSA compared to OSA patients who refused CPAP. In a prospective, observational study of a consecutive cohort of 939 elderly patients ( $\geq 65$ years), the fully adjusted HR for cardiovascular mortality were 2.25 (95\% CI, 1.41-3.61) for the untreated severe OSA group compared with the control group whereas the risk was not increased (HR 0.93; $95 \%$ CI, 0.46-1.89) for the CPAP-treated group (90). A similar study was performed among 1116 women in a sleep-clinic cohort, demonstrating HR of 3.50 (95\% CI, 1.23-9.98) for untreated severe OSA compared with the control group while the risk was not increased for the CPAP-treated group (HR 0.55; 95\% CI, 0.17-1.74) (91). More recently, 
the study of the observational arm of the RICCADSA cohort showed no significant increase in major adverse cardiovascular and cerebrovascular events in CAD patients with sleepy OSA phenotype treated with CPAP compared with the CAD patients without OSA at baseline (adjusted HR 0.96; 95\% CI, 0.40-2.31) (92).

\section{RCTs}

The first RCT for the effect of CPAP on long-term cardiovascular outcomes was conducted in sleep clinic cohorts in Spain. Barbé et al. (93) investigated nonsleepy patients (ESS score $<11$ ) with OSA (AHI $\geq 20 / \mathrm{h}$ ), and free of a CVD at baseline, who were randomized to CPAP $(n=357)$ or no-CPAP $(\mathrm{n}=366)$, and were followed for a median of 4 years. CPAP did not result in a significant reduction in the incidence of the primary composite outcome (nonfatal myocardial infarction, nonfatal stroke, transient ischemic attack, hospitalization for unstable angina or arrhythmia, heart failure, or cardiovascular death) in ITT analysis. However, in post-hoc adherence analysis, patients using the device for at least $4 \mathrm{~h} / \mathrm{night}$ did achieve a benefit (incidence density ratio 0.72 ; $95 \%$ CI, 0.52-0.98) (93).

The second RCT in a sleep clinic cohort was performed by Huang et al. (94), who investigated nonsleepy or mildly sleepy patients $(\mathrm{ESS}<15)$ with OSA $(\mathrm{AHI} \geq 15 / \mathrm{h}$ ), and concomitant hypertension and $\mathrm{CAD}$ at baseline, who were randomized to CPAP $(n=42)$, or no-CPAP $(n=41)$, and were followed for a median of 36 months. CPAP did not result in a significant reduction in the incidence of the primary composite outcome (new-onset acute myocardial infarction, hospitalization for heart failure, coronary revascularization, stroke, and death associated with cardiovascular and cerebrovascular disease) with 1 event in CPAP group, and 5 events in the no-CPAP group, respectively (94). Despite a relatively high adherence to CPAP treatment, the small sample size for the composite outcomes was a major limitation.

The first RCT in a CAD cohort for long-term outcomes was the RICCADSA study (95), which was a single-center trial performed in Sweden between 2005 to 2013. Newly revascularized CAD patients with nonsleepy $(\mathrm{ESS}<10)$ OSA (AHI $\geq 15 / \mathrm{h}$ ) were randomized to auto-titrating CPAP $(n=122)$ or no-CPAP $(n=122)$, and were followed for a median of 57 months. The incidence of the primary composite cardiovascular endpoint (new revascularization, myocardial infarction, stroke or cardiovascular mortality) did not differ between the two groups. However, adjusted on-treatment analysis demonstrated a significant risk reduction in those who used CPAP for at least $4 \mathrm{~h} /$ night (adjusted HR 0.29; 95\% CI, 0.10-0.86) (95).

To date, the largest RCT in CAD and/or cerebrovascular cohorts was the SAVE (Continuous Positive Airway Pressure Treatment of Obstructive Sleep Apnea to Prevent Disease) trial (96). McEvoy et al. enrolled 2,717 nonsleepy or mildly sleepy (ESS $<15$ ) with a history of CAD or cerebrovascular disease and concomitant OSA (oxygen desaturation index $\geq 12 / \mathrm{h}$ on a two-channel home sleep recording device), who were randomized to CPAP or no-CPAP. The primary composite endpoint was cardiovascular death, myocardial infarction, stroke, or hospitalization for unstable angina, heart failure, or transient ischemic attack. After an average follow-up of 3.7 years, a primary end-point event occurred in $17.0 \%$ of the patients in the CPAP group, and in $15.4 \%$ of the patients in no-CPAP (HR for CPAP 1.10; 95\% CI, 0.91-1.32) in the ITT analysis, and there was no significant effect of CPAP on any of the individual cardiovascular endpoints. In the CPAP group, the mean duration of adherence to CPAP therapy was $3.3 \mathrm{~h}$ per night, and $42 \%$ had adequate adherence, defined as CPAP usage $\geq 4 \mathrm{~h} /$ night at 2-year follow-up. One-to-one propensity-score matching was performed to compare 561 patients who were adherent to CPAP therapy with 561 patients in the no-CPAP group. In this secondary analysis, a lower risk of a composite endpoint of cerebral events was found in the CPAP-adherent group (HR 0.52; 95\% CI, 0.30-0.90) (96). The relatively low level of CPAP adherence, especially in patients with established CVD, was suggested to be one of the major limitations in that study (108). Moreover, the use of a two-channel equipment for the OSA diagnosis at baseline was criticized as this device has limitations in differentiating central and obstructive events (3). It was possible that patients with Cheyne-Stokes respiration were included, particularly considering that this kind of breathing disorder is common in patients with stroke and $\mathrm{HF}$ associated with CAD (3).

A recent meta-analysis by Abuzaid et al. (109) including the above mentioned RCTs (93-96) concluded that CPAP utilization to OSA patients was not associated with improved cardiovascular outcomes except in the subgroup that used the device at least $4 \mathrm{~h} /$ night. Another metaanalysis by Yu et al. (110) including 10 trials [9 CPAP and 1 adaptive servo-ventilator (ASV)] reported no evidence of different associations for CPAP vs. ASV, and metaregressions identified no associations of treatment with outcomes for different levels of apnea severity, follow- 
up duration, or adherence to treatment. However, the combination of heterogeneous group of studies including sleep clinic and cardiac and cerebrovascular cohorts, as well as inclusion of adults with OSA and central sleep apnea was pointed out as one of the major methodological concerns that were criticized in another commentary (111).

\section{Evidence level}

The evidence level is scarce to suggest CPAP treatment to nonsleepy or mildly sleepy OSA patients in order to solely reduce risk for long-term cardiovascular outcomes and mortality.

\section{Conclusions}

OSA is a common disorder with increased cardiovascular morbidity and mortality. Despite an accumulating research evidence regarding the beneficial effect of CPAP treatment on cardiovascular outcomes in observational studies, the majority of the recent RCTs have failed to demonstrate convincing evidence for benefits, except in patients with hypertension. It seems that the required level of CPAP adherence is too high to achieve in patients with more advanced CVD such as CAD and stroke, especially when these individuals are nonsleepy. As recently suggested by Drager et al. (112) on behalf of the INCOSACT Initiative (International Collaboration of Sleep Apnea Cardiovascular Trialists), there is a need for further consideration of individual risk factors, and use of new multimodality therapies that also address improvements in adherence. Moreover, a randomization of sleepy OSA patients to no treatment is not ethically feasible since excluding significant sleepiness in CPAP RCTs would mean excluding populations that would benefit from treatment. As previously pointed out, further carefully designed RCTs are needed to overcome the limitations of the recent trials before one may abandon CPAP treatment in OSA patients at risk or with established CVD (111). These goals urge strengthening collaboration among cardiology, sleep medicine, and clinical trial researchers (112). Moreover, as clearly stated in a recent report from an ad hoc working group of the Sleep Disordered Breathing Group of the European Respiratory Society and the European Sleep Research Society (113), future perspectives should consider individual risk factors, and implementation of trials that are appropriately powered to target end-points and to support subgroup analyses. These perspectives also confirm the concept of $\mathrm{P} 4$ medicine as a roadmap for improving care in OSA that is personalised, predictive, preventive and participatory in nature (114).

\section{Acknowledgements}

None.

\section{Footnote}

Conflicts of Interest: Dr. Y Peker reports grants from ResMed, during the conduct of the RICCADSA study mentioned in the current review; personal fees from BresoTec Inc., and personal fees from Philips-Respironics, outside the submitted work. Dr. B Balcan has no conflicts of interest to declare.

\section{References}

1. Heinzer R, Vat S, Marques-Vidal P, et al. Prevalence of sleep-disordered breathing in the general population: the HypnoLaus study. Lancet Respir Med 2015;3:310-8.

2. Berry RB, Budhiraja R, Gottlieb DJ, et al. Rules for scoring respiratory events in sleep: update of the 2007 AASM Manual for the Scoring of Sleep and Associated Events. Deliberations of the Sleep Apnea Definitions Task Force of the American Academy of Sleep Medicine. J Clin Sleep Med 2012;8:597-619.

3. Javaheri S, Barbe F, Campos-Rodriguez F, et al. Sleep Apnea: Types, Mechanisms, and Clinical Cardiovascular Consequences. J Am Coll Cardiol 2017;69:841-58.

4. Khayat R, Pleister A. Consequences of Obstructive Sleep Apnea: Cardiovascular Risk of Obstructive Sleep Apnea and Whether Continuous Positive Airway Pressure Reduces that Risk. Sleep Med Clin 2016;11:273-86.

5. Dedhia RC, Strollo PJ, Soose RJ. Upper Airway Stimulation for Obstructive Sleep Apnea: Past, Present, and Future. Sleep 2015;38:899-906.

6. Tuomilehto HP, Seppa JM, Partinen MM, et al. Lifestyle intervention with weight reduction: first-line treatment in mild obstructive sleep apnea. Am J Respir Crit Care Med 2009;179:320-7.

7. Omobomi O, Quan SF. Positional therapy in the management of positional obstructive sleep apnea-a review of the current literature. Sleep Breath 2018;22:297-304.

8. Hudgel DW. Critical review: CPAP and weight management of obstructive sleep apnea cardiovascular comorbidities. Sleep Med Rev 2018;37:14-23.

9. Halle TR, Oh MS, Collop NA, et al. Surgical Treatment 
of OSA on Cardiovascular Outcomes: A Systematic Review. Chest 2017;152:1214-29.

10. de Vries GE, Wijkstra PJ, Houwerzijl EJ, et al. Cardiovascular effects of oral appliance therapy in obstructive sleep apnea: A systematic review and metaanalysis. Sleep Med Rev 2018;40:55-68.

11. Hedner J, Darpo B, Ejnell H, et al. Reduction in sympathetic activity after long-term CPAP treatment in sleep apnoea: cardiovascular implications. Eur Respir J 1995;8:222-9.

12. Somers VK, Dyken ME, Clary MP, et al. Sympathetic neural mechanisms in obstructive sleep apnea. J Clin Invest 1995;96:1897-904.

13. Heitmann J, Ehlenz K, Penzel T, et al. Sympathetic activity is reduced by nCPAP in hypertensive obstructive sleep apnoea patients. Eur Respir J 2004;23:255-62.

14. Narkiewicz K, Kato M, Phillips BG, et al. Nocturnal continuous positive airway pressure decreases daytime sympathetic traffic in obstructive sleep apnea. Circulation 1999; 100:2332-5.

15. Pinto P, Barbara C, Montserrat JM, et al. Effects of CPAP on nitrate and norepinephrine levels in severe and mildmoderate sleep apnea. BMC Pulm Med 2013;13:13.

16. Henderson LA, Fatouleh RH, Lundblad LC, et al. Effects of 12 Months Continuous Positive Airway Pressure on Sympathetic Activity Related Brainstem Function and Structure in Obstructive Sleep Apnea. Front Neurosci 2016;10:90.

17. Ziegler MG, Mills PJ, Loredo JS, et al. Effect of continuous positive airway pressure and placebo treatment on sympathetic nervous activity in patients with obstructive sleep apnea. Chest 2001;120:887-93.

18. Mills PJ, Kennedy BP, Loredo JS, et al. Effects of nasal continuous positive airway pressure and oxygen supplementation on norepinephrine kinetics and cardiovascular responses in obstructive sleep apnea. J Appl Physiol (1985) 2006;100:343-8.

19. Kohler M, Pepperell JC, Casadei B, et al. CPAP and measures of cardiovascular risk in males with OSAS. Eur Respir J 2008;32:1488-96.

20. Phillips CL, Yee BJ, Marshall NS, et al. Continuous positive airway pressure reduces postprandial lipidemia in obstructive sleep apnea: a randomized, placebocontrolled crossover trial. Am J Respir Crit Care Med 2011;184:355-61.

21. Arias MA, García-Río F, Alonso-Fernández A, et al. CPAP decreases plasma levels of soluble tumour necrosis factoralpha receptor 1 in obstructive sleep apnoea. Eur Respir J
2008;32:1009-15.

22. Alonso-Fernández A, Garcia-Rio F, Arias MA, et al. Effects of CPAP on oxidative stress and nitrate efficiency in sleep apnoea: a randomised trial. Thorax 2009;64:581-6.

23. Arias MA, Garcia-Rio F, Alonso-Fernandez A, et al. Pulmonary hypertension in obstructive sleep apnoea: effects of continuous positive airway pressure: a randomized, controlled cross-over study. Eur Heart J 2006;27:1106-13.

24. Noda A, Nakata S, Koike Y, et al. Continuous positive airway pressure improves daytime baroreflex sensitivity and nitric oxide production in patients with moderate to severe obstructive sleep apnea syndrome. Hypertens Res 2007;30:669-76.

25. Thunström E, Manhem K, Yucel-Lindberg T, et al. Neuroendocrine and Inflammatory Responses to Losartan and Continuous Positive Airway Pressure in Patients with Hypertension and Obstructive Sleep Apnea. A Randomized Controlled Trial. Ann Am Thorac Soc 2016;13:2002-11

26. Carpagnano GE, Kharitonov SA, Resta O, et al. 8-Isoprostane, a marker of oxidative stress, is increased in exhaled breath condensate of patients with obstructive sleep apnea after night and is reduced by continuous positive airway pressure therapy. Chest 2003;124:1386-92.

27. Barceló A, Barbe F, de la Pena M, et al. Antioxidant status in patients with sleep apnoea and impact of continuous positive airway pressure treatment. Eur Respir J 2006;27:756-60.

28. Christou K, Kostikas K, Pastaka C, et al. Nasal continuous positive airway pressure treatment reduces systemic oxidative stress in patients with severe obstructive sleep apnea syndrome. Sleep Med 2009;10:87-94.

29. Takahashi K, Chin K, Nakamura H, et al. Plasma thioredoxin, a novel oxidative stress marker, in patients with obstructive sleep apnea before and after nasal continuous positive airway pressure. Antioxid Redox Signal 2008;10:715-26.

30. Ohga E, Tomita T, Wada H, et al. Effects of obstructive sleep apnea on circulating ICAM-1, IL-8, and MCP-1. J Appl Physiol (1985) 2003;94:179-84.

31. West SD, Nicoll DJ, Wallace TM, et al. Effect of CPAP on insulin resistance and $\mathrm{HbA1c}$ in men with obstructive sleep apnoea and type 2 diabetes. Thorax 2007;62:969-74.

32. Kritikou I, Basta M, Vgontzas AN, et al. Sleep apnoea, sleepiness, inflammation and insulin resistance in middleaged males and females. Eur Respir J 2014;43:145-55.

33. Kohler M, Ayers L, Pepperell JC, et al. Effects of continuous positive airway pressure on systemic 
inflammation in patients with moderate to severe obstructive sleep apnoea: a randomised controlled trial. Thorax 2009;64:67-73.

34. Hoyos CM, Killick R, Yee BJ, et al. Cardiometabolic changes after continuous positive airway pressure for obstructive sleep apnoea: a randomised sham-controlled study. Thorax 2012;67:1081-9.

35. Thunström E, Glantz H, Yucel-Lindberg T, et al. CPAP Does Not Reduce Inflammatory Biomarkers in Patients With Coronary Artery Disease and Nonsleepy Obstructive Sleep Apnea: A Randomized Controlled Trial. Sleep 2017;40.

36. Bayram NA, Ciftci B, Keles T, et al. Endothelial function in normotensive men with obstructive sleep apnea before and 6 months after CPAP treatment. Sleep 2009;32:1257-63.

37. Phillips BG, Narkiewicz K, Pesek CA, et al. Effects of obstructive sleep apnea on endothelin-1 and blood pressure. J Hypertens 1999;17:61-6.

38. Cross MD, Mills NL, Al-Abri M, et al. Continuous positive airway pressure improves vascular function in obstructive sleep apnoea/hypopnoea syndrome: a randomised controlled trial. Thorax 2008;63:578-83.

39. Simpson PJ, Hoyos CM, Celermajer D, et al. Effects of continuous positive airway pressure on endothelial function and circulating progenitor cells in obstructive sleep apnoea: a randomised sham-controlled study. Int J Cardiol 2013;168:2042-8.

40. Ayers L, Stoewhas AC, Ferry B, et al. Elevated levels of endothelial cell-derived microparticles following shortterm withdrawal of continuous positive airway pressure in patients with obstructive sleep apnea: data from a randomized controlled trial. Respiration 2013;85:478-85.

41. Hui DS, Ko FW, Fok JP, et al. The effects of nasal continuous positive airway pressure on platelet activation in obstructive sleep apnea syndrome. Chest 2004;125:1768-75.

42. Chin K, Ohi M, Kita H, et al. Effects of NCPAP therapy on fibrinogen levels in obstructive sleep apnea syndrome. Am J Respir Crit Care Med 1996;153:1972-6.

43. von Känel R, Loredo JS, Ancoli-Israel S, et al. Association between sleep apnea severity and blood coagulability: Treatment effects of nasal continuous positive airway pressure. Sleep Breath 2006;10:139-46.

44. von Känel R, Natarajan L, Ancoli-Israel S, et al. Effect of continuous positive airway pressure on day/night rhythm of prothrombotic markers in obstructive sleep apnea. Sleep Med 2013;14:58-65.
45. Phillips CL, McEwen BJ, Morel-Kopp MC, et al. Effects of continuous positive airway pressure on coagulability in obstructive sleep apnoea: a randomised, placebo-controlled crossover study. Thorax 2012;67:639-44.

46. McEwen BJ, Phillips CL, Morel-Kopp MC, et al. Diurnal changes and levels of fibrin generation are not altered by continuous positive airway pressure (CPAP) in obstructive sleep apnoea (OSA). A randomised, placebo-controlled crossover study. Thromb Haemost 2012;108:701-9.

47. Phillips CL, Yang Q, Williams A, et al. The effect of shortterm withdrawal from continuous positive airway pressure therapy on sympathetic activity and markers of vascular inflammation in subjects with obstructive sleep apnoea. J Sleep Res 2007;16:217-25.

48. Jullian-Desayes I, Joyeux-Faure M, Tamisier R, et al. Impact of obstructive sleep apnea treatment by continuous positive airway pressure on cardiometabolic biomarkers: a systematic review from sham CPAP randomized controlled trials. Sleep Med Rev 2015;21:23-38.

49. Guo Y, Pan L, Ren D, et al. Impact of continuous positive airway pressure on C-reactive protein in patients with obstructive sleep apnea: a meta-analysis. Sleep Breath 2013;17:495-503.

50. Baessler A, Nadeem R, Harvey M, et al. Treatment for sleep apnea by continuous positive airway pressure improves levels of inflammatory markers - a meta-analysis. J Inflamm (Lond) 2013;10:13.

51. Xie X, Pan L, Ren D, et al. Effects of continuous positive airway pressure therapy on systemic inflammation in obstructive sleep apnea: a meta-analysis. Sleep Med 2013;14:1139-50.

52. Kohler M, Stoewhas AC, Ayers L, et al. Effects of continuous positive airway pressure therapy withdrawal in patients with obstructive sleep apnea: a randomized controlled trial. Am J Respir Crit Care Med 2011;184:1192-9.

53. Akashiba T, Minemura H, Yamamoto H, et al. Nasal continuous positive airway pressure changes blood pressure "non-dippers" to "dippers" in patients with obstructive sleep apnea. Sleep 1999;22:849-53.

54. Campos-Rodriguez F, Perez-Ronchel J, Grilo-Reina A, et al. Long-term effect of continuous positive airway pressure on BP in patients with hypertension and sleep apnea.

Chest 2007;132:1847-52.

55. Barnes M, Houston D, Worsnop CJ, et al. A randomized controlled trial of continuous positive airway pressure in mild obstructive sleep apnea. Am J Respir Crit Care Med 2002;165:773-80. 
56. Robinson GV, Smith DM, Langford BA, et al. Continuous positive airway pressure does not reduce blood pressure in nonsleepy hypertensive OSA patients. Eur Respir J 2006;27:1229-35.

57. Muxfeldt ES, Margallo V, Costa LM, et al. Effects of continuous positive airway pressure treatment on clinic and ambulatory blood pressures in patients with obstructive sleep apnea and resistant hypertension: a randomized controlled trial. Hypertension 2015;65:736-42.

58. de Oliveira AC, Martinez D, Massierer D, et al. The antihypertensive effect of positive airway pressure on resistant hypertension of patients with obstructive sleep apnea: a randomized, double-blind, clinical trial. Am J Respir Crit Care Med 2014;190:345-7.

59. Martínez-García MA, Capote F, Campos-Rodriguez F, et al. Effect of CPAP on blood pressure in patients with obstructive sleep apnea and resistant hypertension: the HIPARCO randomized clinical trial. JAMA 2013;310:2407-15.

60. Pedrosa RP, Drager LF, de Paula LKG, et al. Effects of OSA treatment on BP in patients with resistant hypertension: a randomized trial. Chest 2013;144:1487-94.

61. Lozano L, Tovar JL, Sampol G, et al. Continuous positive airway pressure treatment in sleep apnea patients with resistant hypertension: a randomized, controlled trial. J Hypertens 2010;28:2161-8.

62. Durán-Cantolla J, Aizpuru F, Montserrat JM, et al. Continuous positive airway pressure as treatment for systemic hypertension in people with obstructive sleep apnoea: randomised controlled trial. BMJ 2010;341:c5991.

63. Pépin JL, Tamisier R, Barone-Rochette G, et al. Comparison of continuous positive airway pressure and valsartan in hypertensive patients with sleep apnea. Am J Respir Crit Care Med 2010;182:954-60.

64. Thunström E, Manhem K, Rosengren A, et al. Blood Pressure Response to Losartan and Continuous Positive Airway Pressure in Hypertension and Obstructive Sleep Apnea. Am J Respir Crit Care Med 2016;193:310-20.

65. Alchanatis M, Tourkohoriti G, Kakouros S, et al. Daytime pulmonary hypertension in patients with obstructive sleep apnea: the effect of continuous positive airway pressure on pulmonary hemodynamics. Respiration 2001;68:566-72.

66. Sajkov D, Wang T, Saunders NA, et al. Continuous positive airway pressure treatment improves pulmonary hemodynamics in patients with obstructive sleep apnea. Am J Respir Crit Care Med 2002;165:152-8.

67. Kanagala R, Murali NS, Friedman PA, et al. Obstructive sleep apnea and the recurrence of atrial fibrillation.
Circulation 2003;107:2589-94.

68. Fein AS, Shvilkin A, Shah D, et al. Treatment of obstructive sleep apnea reduces the risk of atrial fibrillation recurrence after catheter ablation. J Am Coll Cardiol 2013;62:300-5.

69. Neilan TG, Farhad H, Dodson JA, et al. Effect of sleep apnea and continuous positive airway pressure on cardiac structure and recurrence of atrial fibrillation. J Am Heart Assoc 2013;2:e000421.

70. Naruse Y, Tada H, Satoh M, et al. Concomitant obstructive sleep apnea increases the recurrence of atrial fibrillation following radiofrequency catheter ablation of atrial fibrillation: clinical impact of continuous positive airway pressure therapy. Heart Rhythm 2013;10:331-7.

71. Holmqvist F, Guan N, Zhu Z, et al. Impact of obstructive sleep apnea and continuous positive airway pressure therapy on outcomes in patients with atrial fibrillationResults from the Outcomes Registry for Better Informed Treatment of Atrial Fibrillation (ORBIT-AF). Am Heart J 2015;169:647-54.e2.

72. Harbison J, O'Reilly P, McNicholas WT. Cardiac rhythm disturbances in the obstructive sleep apnea syndrome: effects of nasal continuous positive airway pressure therapy. Chest 2000;118:591-5.

73. Roche F, Barthelemy JC, Garet M, et al. Continuous positive airway pressure treatment improves the QT rate dependence adaptation of obstructive sleep apnea patients. Pacing Clin Electrophysiol 2005;28:819-25.

74. Ryan CM, Usui K, Floras JS, et al. Effect of continuous positive airway pressure on ventricular ectopy in heart failure patients with obstructive sleep apnoea. Thorax 2005;60:781-5.

75. Javaheri S. Effects of continuous positive airway pressure on sleep apnea and ventricular irritability in patients with heart failure. Circulation 2000;101:392-7.

76. Shivalkar B, Van de Heyning C, Kerremans M, et al. Obstructive sleep apnea syndrome: more insights on structural and functional cardiac alterations, and the effects of treatment with continuous positive airway pressure. J Am Coll Cardiol 2006;47:1433-9.

77. Kasai T, Narui K, Dohi T, et al. Prognosis of patients with heart failure and obstructive sleep apnea treated with continuous positive airway pressure. Chest 2008;133:690-6.

78. Akar Bayram N, Ciftci B, Durmaz T, et al. Effects of continuous positive airway pressure therapy on left ventricular function assessed by tissue Doppler imaging in patients with obstructive sleep apnoea syndrome. Eur J 
Echocardiogr 2009;10:376-82.

79. Kaneko Y, Floras JS, Usui K, et al. Cardiovascular effects of continuous positive airway pressure in patients with heart failure and obstructive sleep apnea. N Engl J Med 2003;348:1233-41.

80. Usui K, Bradley TD, Spaak J, et al. Inhibition of awake sympathetic nerve activity of heart failure patients with obstructive sleep apnea by nocturnal continuous positive airway pressure. J Am Coll Cardiol 2005;45:2008-11.

81. Hall AB, Ziadi MC, Leech JA, et al. Effects of shortterm continuous positive airway pressure on myocardial sympathetic nerve function and energetics in patients with heart failure and obstructive sleep apnea: a randomized study. Circulation 2014;130:892-901.

82. Arias MA, Garcia-Rio F, Alonso-Fernandez A, et al. Obstructive sleep apnea syndrome affects left ventricular diastolic function: effects of nasal continuous positive airway pressure in men. Circulation 2005;112:375-83.

83. Glantz H, Johansson MC, Thunström E, et al. Effect of CPAP on diastolic function in coronary artery disease patients with nonsleepy obstructive sleep apnea: A randomized controlled trial. Int J Cardiol 2017;241:12-8.

84. Peker Y, Carlson J, Hedner J. Increased incidence of coronary artery disease in sleep apnoea: a long-term follow-up. Eur Respir J 2006;28:596-602.

85. Marin JM, Carrizo SJ, Vicente E, et al. Long-term cardiovascular outcomes in men with obstructive sleep apnoea-hypopnoea with or without treatment with continuous positive airway pressure: an observational study. Lancet 2005;365:1046-53.

86. Doherty LS, Kiely JL, Swan V, et al. Long-term effects of nasal continuous positive airway pressure therapy on cardiovascular outcomes in sleep apnea syndrome. Chest 2005;127:2076-84.

87. Buchner NJ, Sanner BM, Borgel J, et al. Continuous positive airway pressure treatment of mild to moderate obstructive sleep apnea reduces cardiovascular risk. Am J Respir Crit Care Med 2007;176:1274-80.

88. Cassar A, Morgenthaler TI, Lennon RJ, et al. Treatment of obstructive sleep apnea is associated with decreased cardiac death after percutaneous coronary intervention. J Am Coll Cardiol 2007;50:1310-4.

89. Milleron O, Pilliere R, Foucher A, et al. Benefits of obstructive sleep apnoea treatment in coronary artery disease: a long-term follow-up study. Eur Heart J 2004;25:728-34.

90. Martínez-García MA, Campos-Rodriguez F, Catalan-Serra $\mathrm{P}$, et al. Cardiovascular mortality in obstructive sleep apnea in the elderly: role of long-term continuous positive airway pressure treatment: a prospective observational study. Am J Respir Crit Care Med 2012;186:909-16.

91. Campos-Rodriguez F, Martinez-Garcia MA, de la CruzMoron I, et al. Cardiovascular mortality in women with obstructive sleep apnea with or without continuous positive airway pressure treatment: a cohort study. Ann Intern Med 2012;156:115-22.

92. Peker Y, Thunström E, Glantz H, et al. Outcomes in coronary artery disease patients with sleepy obstructive sleep apnoea on CPAP. Eur Respir J 2017;50.

93. Barbé F, Durán-Cantolla J, Sánchez-de-la-Torre M, et al. Effect of continuous positive airway pressure on the incidence of hypertension and cardiovascular events in nonsleepy patients with obstructive sleep apnea: a randomized controlled trial. JAMA 2012;307:2161-8.

94. Huang Z, Liu Z, Luo Q, et al. Long-term effects of continuous positive airway pressure on blood pressure and prognosis in hypertensive patients with coronary heart disease and obstructive sleep apnea: a randomized controlled trial. Am J Hypertens 2015;28:300-6.

95. Peker Y, Glantz H, Eulenburg C, et al. Effect of Positive Airway Pressure on Cardiovascular Outcomes in Coronary Artery Disease Patients with Nonsleepy Obstructive Sleep Apnea. The RICCADSA Randomized Controlled Trial. Am J Respir Crit Care Med 2016;194:613-20.

96. McEvoy RD, Antic NA, Heeley E, et al. CPAP for Prevention of Cardiovascular Events in Obstructive Sleep Apnea. N Engl J Med 2016;375:919-31.

97. Haentjens P, Van Meerhaeghe A, Moscariello A, et al. The impact of continuous positive airway pressure on blood pressure in patients with obstructive sleep apnea syndrome: evidence from a meta-analysis of placebo-controlled randomized trials. Arch Intern Med 2007;167:757-64.

98. Bratton DJ, Stradling JR, Barbe F, et al. Effect of CPAP on blood pressure in patients with minimally symptomatic obstructive sleep apnoea: a meta-analysis using individual patient data from four randomised controlled trials. Thorax 2014;69:1128-35.

99. Bakker JP, Edwards BA, Gautam SP, et al. Blood pressure improvement with continuous positive airway pressure is independent of obstructive sleep apnea severity. J Clin Sleep Med 2014;10:365-9. Erratum in: J Clin Sleep Med 2014;10:711. Barandiarán, Felipe Aizpuru [corrected to Aizpuru, Felipe].

100.Alajmi M, Mulgrew AT, Fox J, et al. Impact of continuous positive airway pressure therapy on blood pressure in patients with obstructive sleep apnea hypopnea: a 
meta-analysis of randomized controlled trials. Lung 2007;185:67-72.

101. Montesi SB, Edwards BA, Malhotra A, et al. The effect of continuous positive airway pressure treatment on blood pressure: a systematic review and meta-analysis of randomized controlled trials. J Clin Sleep Med 2012;8:587-96.

102. Bazzano LA, Khan Z, Reynolds K, et al. Effect of nocturnal nasal continuous positive airway pressure on blood pressure in obstructive sleep apnea. Hypertension 2007;50:417-23.

103.Liu L, Cao Q, Guo Z, et al. Continuous Positive Airway Pressure in Patients With Obstructive Sleep Apnea and Resistant Hypertension: A Meta-Analysis of Randomized Controlled Trials. J Clin Hypertens (Greenwich) 2016;18:153-8.

104. Iftikhar IH, Valentine CW, Bittencourt LR, et al. Effects of continuous positive airway pressure on blood pressure in patients with resistant hypertension and obstructive sleep apnea: a meta-analysis. J Hypertens 2014;32:234150; discussion 2350.

105.Javaheri S, Javaheri S, Javaheri A. Sleep apnea, heart failure, and pulmonary hypertension. Curr Heart Fail Rep 2013;10:315-20.

106. Qureshi WT, Nasir UB, Alqalyoobi S, et al. Meta-Analysis of Continuous Positive Airway Pressure as a Therapy of Atrial Fibrillation in Obstructive Sleep Apnea. Am J Cardiol 2015;116:1767-73.

107.Calkins H, Hindricks G, Cappato R, et al. 2017 HRS/EHRA/ECAS/APHRS/SOLAECE expert consensus statement on catheter and surgical ablation of atrial fibrillation: Executive summary. J Arrhythm 2017;33:369-409.

108. Peker Y, Strollo PJ Jr. CPAP did not reduce cardiovascular events in patients with coronary or cerebrovascular disease and moderate to severe obstructive sleep apnoea. Evid Based Med 2017;22:67-8.

109.Abuzaid AS, Al Ashry HS, Elbadawi A, et al. Meta-Analysis of Cardiovascular Outcomes With Continuous Positive Airway Pressure Therapy in Patients With Obstructive Sleep Apnea. Am J Cardiol 2017;120:693-9.

110. Yu J, Zhou Z, McEvoy RD, et al. Association of Positive Airway Pressure With Cardiovascular Events and Death in Adults With Sleep Apnea: A Systematic Review and Metaanalysis. JAMA 2017;318:156-66.

111.Peker Y, Strollo PJ Jr. A meta-analysis of positive airway pressure treatment for cardiovascular prevention: why mix apples and pears?. Evid Based Med 2017;22:218-9.

112.Drager LF, McEvoy RD, Barbe F, et al. Sleep Apnea and Cardiovascular Disease: Lessons From Recent Trials and Need for Team Science. Circulation 2017;136:1840-50.

113. Randerath W, Bassetti CL, Bonsignore MR, et al. Challenges and perspectives in obstructive sleep apnoea: Report by an ad hoc working group of the Sleep Disordered Breathing Group of the European Respiratory Society and the European Sleep Research Society. Eur Respir J 2018;52.

114. Pack AI. Application of Personalized, Predictive, Preventative, and Participatory (P4) Medicine to Obstructive Sleep Apnea. A Roadmap for Improving Care? Ann Am Thorac Soc 2016;13:1456-67.
Cite this article as: Peker T, Balcan B. Cardiovascular outcomes of continuous positive airway pressure therapy for obstructive sleep apnea. J Thorac Dis 2018;10(Suppl 34):S4262S4279. doi: $10.21037 /$ jtd.2018.11.48 